\title{
Desempenho em confinamento de bovinos de corte, castrados ou não, alimentados com teores crescentes de farelo do mesocarpo de babaçu
}

\author{
Performance in feedlot beef cattle, bulls or not, fed with increasing levels of babassu mesocarp meal
}

\author{
Nelson Rafael da Silva ${ }^{\mathrm{I}}$ Ana Cristina Holanda Ferreira ${ }^{\mathrm{II}}$ Cristian Faturi ${ }^{\mathrm{III}}$ Gerson Fausto da Silva ${ }^{\mathrm{II}}$ \\ Regis Luis Missio ${ }^{\text {IV }}$ José Neuman Miranda Neiva $^{\text {II }}$ Vera Lúcia de Araújo ${ }^{\text {II }}$ Emerson Alexandrino ${ }^{\text {II }}$
}

\section{RESUMO}

Objetivou-se avaliar quatro teores de inclusão de farelo do mesocarpo de babaçu (Orbygnya spp.) no concentrado sobre o desempenho de bovinos confinados. Foram utilizados 24 bovinos machos (12 castrados e 12 não castrados) com idade e peso corporal médio de 33 meses e 332,1 $124 \mathrm{~kg}$, respectivamente. As dietas foram isonitrogenadas, compostas por $44 \%$ de silagem de capim Mombaça e $56 \%$ de concentrado na matéria seca. $O$ grão de milho do concentrado foi substituído pelo farelo do mesocarpo de babaçu em 0, 20,40 e 60\% da matéria seca. $O$ delineamento experimental utilizado foi blocos inteiramente casualisados, com os tratamentos dispostos num fatorial $4 \times 2$ (quatro níveis de inclusão de farelo do mesocarpo de babaçu e duas condições sexuais). $O$ consumo de matéria seca, em $\mathrm{kg}$ dia $^{-1}$ e percentagem do peso corporal, não foi alterado pelos níveis de inclusão de farelo do mesocarpo de babaçu, com valores médios de $9,37 \mathrm{~kg}$ e 2,54\%, respectivamente. Os teores de inclusão de farelo do mesocarpo de babaçu não influenciaram no ganho de peso diário e na conversão alimentar, sendo os valores médios de $1,157 \mathrm{~kg} \mathrm{dia}^{-1}$ e 8,39kg de matéria seca $\mathrm{kg}^{-1}$ de ganho de peso. Os novilhos não castrados apresentaram maior ganho de peso médio diário $\left(1,259 \mathrm{~kg} \mathrm{dia}^{-1}\right)$ que os castrados $\left(1.066 \mathrm{~kg} \mathrm{dia}^{-1}\right)$, refletindo a melhor conversão alimentar (7,702 e 9,094kg de matéria seca $\mathrm{kg}^{-1}$ de ganho de peso, respectivamente). O farelo do mesocarpo de babaçu como fonte energética alternativa, pode ser utilizado para bovinos confinados em até $60 \%$ de inclusão no concentrado, em substituição ao grão de milho.

Palavras-chave: conversão alimentar, ganho de peso diário, machos castrados, machos não castrados.

\section{ABSTRACT}

The objective was to evaluate four levels of inclusion of babassu mesocarp meal (Orbygnya spp.) in the concentrate on cattle feedlot performance. Twenty four animals (12 steers and 12 bulls) were used with age and body weight of 33 months and $332.1 \pm 24 \mathrm{~kg}$, respectively. Diets were isonitrogenous, composed of $44 \%$ of Mombasa grass silage and $56 \%$ of concentrate in dry matter. Corn grain of the concentrate fraction was replaced by babassu mesocarp meal at 0, 20, 40 and 60\% in dry matter. The experimental design was randomized complete block, with factorial arrangement of treatments $4 \times 2$ (four levels of babassu mesocarp meal inclusion and two sexual conditions). Dry matter intake in $\mathrm{kg}$ day ${ }^{l}$ and percentage of body weight was not altered by the inclusion level of bran babassu mesocarp, with average values of $9.37 \mathrm{~kg} \mathrm{day}^{-1}$ and $2.54 \%$ respectively. Inclusion levels of babassu mesocarp meal did not affect daily weight gain and feed conversion the animals, with average values of $1.157 \mathrm{~kg} \mathrm{day}^{-1}$ and $8.39 \mathrm{~kg}$ of dry matter $\mathrm{kg}^{-1}$ weight gain. Bulls had higher daily weight gain $(1.259 \mathrm{~kg}$ day $\left.{ }^{-1}\right)$ than steers $\left(1.066 \mathrm{~kg} \mathrm{day}^{-1}\right)$, reflecting a better feed conversion $\left(7.702\right.$ and $9.094 \mathrm{~kg}$ dry matter $\mathrm{kg}^{-1}$ weight gain, respectively). Babassu mesocarp meal, such as alternative energy source, can be fed to feedlot to the $60 \%$ level of inclusion in the concentrate, replacing corn grain.

Key words: bulls, daily weight gain, feed conversion, steers.

\section{INTRODUÇÃO}

A utilização de subprodutos da agroindústria na alimentação de bovinos não é prática recente, tendo sido aumentada devido à crescente preocupação com as questões ambientais e elevação do preço da principal fonte energética (grão de milho),

\footnotetext{
'Programa de Pós-graduação em Ciência Animal Tropical, Fundação Universidade Federal do Tocantins (UFT), Araguaína, TO, Brasil. "UFT, Araguaína, TO, Brasil.

"IUniversidade Federal Rural da Amazônia (UFRA), Belém, PA, Brasil.

IVPrograma de Pós-graduação em Ciência Animal Tropical, UFT, BR 153, Km 112, Zona Rural, s/n, 77804-970, Araguaína, TO, Brasil. E-mail: regisluismissio@gmail.com. Autor para correspondência.
} 
devido à demanda para produção de biocombustíveis. Atualmente, os EUA destinam $40 \%$ da sua produção de milho para a produção de biocombustíveis (WILKINSON, 2010), alterando os preços internacionais de commodities, como o grão de milho e o farelo de soja, usados na alimentação animal.

$\mathrm{Na}$ busca por maior lucratividade na terminação de bovinos em confinamento, deve-se priorizar a redução do custo com alimentação, já que esse componente é o mais expressivo no custo quando desconsiderado o valor de compra do animal, superando $70 \%$ do total, sendo o concentrado o componente mais oneroso da dieta (PACHECO et al., 2006; RESTLE et al., 2007; MISSIO et al., 2009). Sendo assim, a utilização de subprodutos da agroindústria, para substituir total ou parcialmente o milho da dieta, pode representar avanços para a alimentação de bovinos em confinamento.

O babaçu (Orbynia speciosa) é uma palmeira nativa encontrada principalmente na região Norte, Nordeste e Centro-oeste do Brasil. Segundo SILVA (2008) o fruto do babaçu apresenta $11 \%$ de epicarpo, $23 \%$ de mesocarpo, $59 \%$ de endocarpo e $7 \%$ de amêndoas. A importância do babaçu para a economia da região está relacionada com a produção de farinha para consumo humano, óleo e fonte de alimento e sombra para os animais. Além disso, a partir do mesocarpo do coco do babaçu é produzido o farelo do mesocarpo do babaçu, o qual é ofertado no mercado a baixo custo. Tal fato tem promovido o interesse para seu fornecimento na alimentação animal. Todavia, são raros os estudos com este subproduto, sendo basicamente existentes pesquisas que avaliaram suas características nutricionais (SILVA, 2008; GUIMARÃES, 2010). Sendo assim, objetivou-se com o presente estudo avaliar o efeito da inclusão de diferentes teores de farelo do mesocarpo de babaçu no concentrado sobre o desempenho produtivo de bovinos confinados.

\section{MATERIAL E MÉTODOS}

O delineamento experimental utilizado foi o de blocos inteiramente casualisados com os tratamentos em arranjo fatorial $4 \times 2$ (quatro teores de inclusão de farelo do mesocarpo de babaçu e duas condições sexuais). Para isso, foram utilizados 24 animais da raça Nelore (12 castrados e 12 não castrados), contemporâneos, com 33 meses de idade e peso médio de $332,1 \pm 24 \mathrm{~kg}$, provenientes do mesmo rebanho, manejados em pastagem de Brachiaria brizanta cv. 'Marandu' até o início do experimento. Os animais foram submetidos ao controle de endoparasitas e ectoparasitas antes do início do período experimental e, durante o experimento através de aplicação de pouron para controle de moscas. Para início do experimento, os animais foram confinados em baias individuais $\left(16 \mathrm{~m}^{2}\right)$ parcialmente cobertas, com piso de concreto, equipadas com bebedouros e comedouros individualizados, sendo adaptados às dietas (Tabela 1) e instalações por 21 dias.

O período de confinamento foi de 84 dias, dividido em três períodos de 28 dias. Os animais foram pesados no início e final de cada período experimental, após jejum de sólidos e líquidos de 14 horas. Os animais foram alimentados duas vezes ao dia ( $08 \mathrm{~h}$ e $16 \mathrm{~h}$ ), sendo o concentrado e o volumoso pesados separadamente e misturados no comedouro. Para o ajuste da oferta de alimentos, todos os dias antes da primeira refeição, as sobras eram retiradas e pesadas, sendo a quantidade de sobras mantida em torno de $10 \%$ do ofertado.

As dietas foram formuladas para serem isonitrogenadas (12\% de proteína bruta), com de $44 \%$ de capim Mombaça como único volumoso (Tabela 1). Os tratamentos foram constituídos das dietas experimentais, em que foram avaliados teores crescentes (0; 20; 40 e 60\%) de inclusão de farelo do mesocarpo de babaçu no concentrado. Semanalmente, os alimentos e sobras foram amostrados, sendo as amostras présecas em estufa de ar forçado à $55^{\circ} \mathrm{C}$ por 72 horas e moídas em moinho tipo Willey, com peneiras com crivos de 0,6mm. Após, os alimentos foram analisados quanto a sua composição (Tabela 2) e, posteriormente, calculada a composição das dietas (Tabela 1).

O teor de matéria seca, matéria mineral (MM), proteína bruta $(\mathrm{PB})$ e extrato etéreo (EE) foram determinados segundo AOAC (1990). Os teores de fibra em detergente neutro (FDN) foram determinados segundo VAN SOEST et al. (1991). O teor de carboidratos totais (CT), carboidratos não fibrosos (CNF) e nutrientes digestíveis totais (NDT) foram determinados segundo SNIFFEN et al. (1992), em que CT $=100-(\% \mathrm{~PB}+\% \mathrm{EE}+$ $\% \mathrm{MM}), \mathrm{CNF}=\mathrm{CT}-\mathrm{FDNe} \mathrm{NDT}(\%)=\mathrm{PBD} \%+\mathrm{FDND} \%$ $+\mathrm{CNFD} \%+(2,25 \times \mathrm{EED} \%)$.

Os dados foram submetidos à análise de variância e regressão polinomial, considerando-se 5\% como nível crítico de significância. As análises foram realizadas através do programa estatístico SAS (1993).

\section{RESULTADOS E DISCUSSÃO}

Foi verificada ausência de interação significativa $(\mathrm{P}>0,05)$ entre os teores de farelo do mesocarpo do babaçu no concentrado e condição sexual para as variáveis relacionadas com o consumo das frações alimentares e desempenho animal. Dessa forma, os resultados foram apresentados em separado de acordo com os efeitos principais. 
Tabela 1 - Composição centesimal e química das dietas experimentais.

\begin{tabular}{|c|c|c|c|c|}
\hline \multirow{2}{*}{ Itens } & \multirow[b]{2}{*}{0} & \multirow[b]{2}{*}{20} & \multirow[b]{2}{*}{40} & \multirow[b]{2}{*}{60} \\
\hline & & & & \\
\hline Silagem de capim Mombaça $^{1}$ & 44,00 & 44,00 & 44,00 & 44,00 \\
\hline Grão de milho triturado ${ }^{1}$ & 43,68 & 30,58 & 17,75 & 4,76 \\
\hline Farelo de soja ${ }^{1}$ & 11,2 & 13,1 & 14,73 & 16,52 \\
\hline Farelo do mesocarpo do babaçu & 0,00 & 11,20 & 22,40 & 33,60 \\
\hline Calcário calcítico ${ }^{2}$ & 0,56 & 0,56 & 0,56 & 0,56 \\
\hline Sal mineral $^{3}$ & 0,56 & 0,56 & 0,56 & 0,56 \\
\hline Matéria seca ${ }^{4}$ & 59,94 & $\begin{array}{l}\text { Io quim } 1 \\
59,70\end{array}$ & 59,46 & 59,23 \\
\hline Proteína bruta ${ }^{1}$ & 14,49 & 14,40 & 14,20 & 14,07 \\
\hline Fibra em detergente neutro ${ }^{1}$ & 33,07 & 37,22 & 41,35 & 45,49 \\
\hline Fibra em detergente ácido ${ }^{1}$ & 17,80 & 18,78 & 19,75 & 20,73 \\
\hline Carboidratos totais ${ }^{1}$ & 78,76 & 94,88 & 43,99 & 85,06 \\
\hline Carboidratos não fibrosos ${ }^{1}$ & 16,65 & 49,32 & 30,00 & 72,90 \\
\hline Nutrientes digestíveis totais ${ }^{1}$ & 65,00 & 76,13 & 81,54 & 85,00 \\
\hline
\end{tabular}

${ }^{1}$ Valores expressos em percentagem da matéria seca; ${ }^{2}$ níveis de garantia: $\mathrm{CaO}=37 \%$; $\mathrm{MgO}=6 \%$; $\mathrm{CaOo}+\mathrm{Mg}=43 \%$; ${ }^{3}$ níveis de garantia (concentração $\mathrm{kg}^{-1}$ ): $\mathrm{P}=40 \mathrm{~g}, \mathrm{Ca}=52 \mathrm{~g}, \mathrm{~S}=20 \mathrm{~g}, \mathrm{Mg}=6,5 \mathrm{~g}, \mathrm{Mn}=600 \mathrm{mg}, \mathrm{Cu}=500 \mathrm{mg}, \mathrm{Zn}=3.500 \mathrm{mg}, \mathrm{Co}=80 \mathrm{mg}, \mathrm{Se}=15 \mathrm{mg}, \mathrm{I}=40 \mathrm{mg}$ e Cloro/sódio q.s.p $1000 \mathrm{mg} ;{ }^{4}$ valor expresso em percentagem da matéria natural. O teor de matéria mineral das dietas foi determinado levando em consideração sua concentração nos alimentos e os níveis de garantia do sal mineral e calcário calcítico.

O consumo de matéria seca não foi alterado $(\mathrm{P}>0,05)$ pelo aumento do teor de farelo do mesocarpo do babaçu na dieta (Tabela 3). Esses resultados podem ser justificados pelo fato de as dietas utilizadas serem isonitrogenadas e por não terem proporcionado limitação quanto ao consumo de fibra em detergente neutro (Tabela 1). Destaca-se que o consumo de fibra em detergente neutro considerado ótimo para máxima atividade ruminal é de $1,2 \%$ do peso corporal (MERTENS, 1994). Os resultados referentes ao consumo demonstram que o farelo do mesocarpo do babaçu não apresenta restrições quanto à aceitabilidade e palatabilidade, podendo ser incluído em até $60 \%$ na substituição do milho do concentrado para alimentação de bovinos confinados.

Em virtude da semelhança de consumo de matéria seca e similar teor proteico das dietas, o consumo de proteína bruta não foi alterado $(\mathrm{P}>0,05)$ pelo aumento do teor de farelo do mesocarpo de babaçu no concentrado (Tabela 3). Por outro lado, a inclusão

Tabela 2 - Composição do volumoso e ingredientes do concentrado.

\begin{tabular}{|c|c|c|c|c|}
\hline \multirow{2}{*}{ Itens } & \multirow[b]{2}{*}{ Silagem $^{3}$} & \multirow[b]{2}{*}{ Farelo babaçu ${ }^{4}$} & \multirow[b]{2}{*}{ Farelo de soja $^{5}$} & \multirow[b]{2}{*}{ Grão de milho ${ }^{6}$} \\
\hline & & & & \\
\hline Matéria seca $^{1}$ & 26,13 & 85,68 & 89,26 & 88,00 \\
\hline Matéria mineral $^{2}$ & 8,59 & 1,23 & 6,32 & 1,14 \\
\hline Proteína bruta $^{2}$ & 11,09 & 2,01 & 48,78 & 9,50 \\
\hline Extrato etéreo $^{2}$ & 1,56 & 1,88 & 1,71 & 4,30 \\
\hline Fibra em detergente neutro ${ }^{2}$ & 62,10 & 45,56 & 14,62 & 9,40 \\
\hline Fibra em detergente ácido ${ }^{2}$ & 34,72 & 10,85 & 9,86 & 3,20 \\
\hline Carboidratos totais ${ }^{2}$ & 78,76 & 94,88 & 43,99 & 85,06 \\
\hline Carboidratos não fibrosos ${ }^{2}$ & 16,65 & 49,32 & 30,00 & 72,90 \\
\hline Nutrientes digestíveis totais ${ }^{2}$ & 65,00 & 76,13 & 81,54 & 85,00 \\
\hline
\end{tabular}

${ }^{1}$ Valor expresso em percentagem da matéria natural; ${ }^{2}$ valores expressos em percentagem da matéria seca; ${ }^{3}$ silagem de capim Mombaça; ${ }^{4}$ farelo do mesocarpo de babaçu; ${ }^{5}$ composição estimada segundo VALADARES et al. (2006); ${ }^{6}$ grão de milho moído.

Ciência Rural, v.42, n.10, out, 2012. 
Tabela 3 - Consumo das frações alimentares por bovinos confinados alimentados com teores crescentes de farelo do mesocarpo do babaçu no concentrado.

\begin{tabular}{|c|c|c|c|c|c|c|c|c|}
\hline \multirow{2}{*}{ Itens } & \multicolumn{4}{|c|}{---1---Farelo do mesocarpo do babaçu, \%---- } & \multirow{2}{*}{ Equação de regressão } & \multirow{2}{*}{$\mathrm{R}^{2}$} & \multirow{2}{*}{$\mathrm{CV}, \%$} & \multirow{2}{*}{$\mathrm{P}$} \\
\hline & 0 & 20 & 40 & 60 & & & & \\
\hline & \multicolumn{8}{|c|}{ 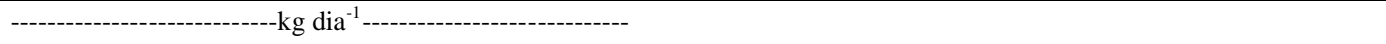 } \\
\hline CMS & 9,122 & 9,908 & 9,213 & 9,929 & $\hat{\mathrm{Y}}=9,368$ & - & 10,0 & 0,239 \\
\hline $\mathrm{CPB}$ & 1,242 & 1,386 & 1,223 & 1,364 & $\hat{Y}=1,303$ & - & 9,9 & 0,301 \\
\hline CFDN & 3,304 & 3,997 & 3,973 & 4,608 & $\hat{\mathrm{Y}}=3,404+0,02028 \mathrm{X}_{\mathrm{ni}}$ & 0,55 & 10,7 & 0,001 \\
\hline \multirow[t]{2}{*}{$\mathrm{CCNF}$} & 3,845 & 3,692 & 3,292 & 3,106 & $\hat{\mathrm{Y}}=3,8906-0,01234 \mathrm{X}_{\mathrm{ni}}$ & 0,41 & 9,7 & 0,001 \\
\hline & & $----g$ kg & $-x-y$ & & & & & \\
\hline CMS & 113,6 & 117,11 & 106,77 & 120,37 & $\hat{\mathrm{Y}}=114,46$ & - & 13,3 & 0,113 \\
\hline $\mathrm{CPB}$ & 14,15 & 16,44 & 14,28 & 16,61 & $\hat{\mathrm{Y}}=15,37$ & - & 13,3 & 0,135 \\
\hline CFDN & 37,55 & 47,35 & 46,07 & 55,76 & $\hat{\mathrm{Y}}=38,8974+0,2778 \mathrm{X}_{\mathrm{ni}}$ & 0,48 & 14,2 & 0,001 \\
\hline \multirow[t]{2}{*}{$\mathrm{CCNF}$} & 43,56 & 43,42 & 37,95 & 37,60 & $\hat{\mathrm{Y}}=44,3123-0,1073 \mathrm{X}_{\mathrm{ni}}$ & 0,19 & 12,8 & 0,036 \\
\hline & 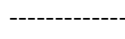 & $-\%$ do pe & poral---- & ------------ & & & & \\
\hline CMS & 2,33 & 2,67 & 2,42 & 2,77 & $\hat{Y}=2,54$ & - & 14,7 & 0,099 \\
\hline CPB & 0,32 & 0,37 & 0,32 & 0,38 & $\hat{\mathrm{Y}}=0,34$ & - & 14,8 & 0,115 \\
\hline CFDN & 0,84 & 1,08 & 1,04 & 1,25 & $\hat{\mathrm{Y}}=0,8825+0,00622 \mathrm{X}_{\mathrm{ni}}$ & 0,40 & 16,5 & 0,001 \\
\hline $\mathrm{CCNF}$ & 0,98 & 0,99 & 0,86 & 0,86 & $\hat{\mathrm{Y}}=0,92$ & - & 14,2 & 0,088 \\
\hline
\end{tabular}

CMS, CPB, CFDN e CCNF = consumo de matéria seca, proteína bruta, fibra em detergente neutro e carboidratos não fibrosos, respectivamente; $\mathrm{PC}=$ peso corporal; $\mathrm{R}^{2}=$ coeficiente de determinação; $\mathrm{CV}=$ coeficiente de variação; $\mathrm{P}=$ probabilidade; $\mathrm{Y}=\mathrm{Valores}$ estimados; $\mathrm{X}_{\mathrm{ni}}=$ teor de farelo do mesocarpo de babaçu no concentrado.

de farelo do mesocarpo de babaçu elevou o teor de fibra em detergente neutro em relação à dieta sem inclusão desse subproduto (Tabela 1), elevando linearmente $(\mathrm{P}<0,05)$ o consumo dessa fração nutritiva, aumentando aproximadamente $0,02 \mathrm{~kg} \mathrm{dia}^{-1} ; 0,28 \mathrm{~g} \mathrm{~kg}^{-1}$ de peso metabólico $\left(\mathrm{PC}^{0,75}\right)$ e $0,006 \%$ do peso corporal a cada ponto percentual a mais na inclusão de farelo do mesocarpo de babaçu no concentrado (Tabela 3 ). Já o consumo de carboidratos não fibrosos apresentou ajuste $(\mathrm{P}<0,05)$ para equação de regressão linear, com exceção do consumo em função do peso corporal, reduzindo $0,01 \mathrm{~kg} \mathrm{dia}^{-1}$ e $0,11 \mathrm{~g} \mathrm{~kg}^{-1} \mathrm{PC}^{0,75}$ a cada ponto percentual de inclusão de farelo do mesocarpo de babaçu no concentrado. Tais resultados estão associados com a diminuição dos carboidratos não fibrosos das dietas, em virtude da substituição do grão de milho pelo farelo do mesocarpo de babaçu, o qual se caracteriza pelo menor teor destes carboidratos e maior quantidade de carboidratos fibrosos que o grão de milho (Tabela 2).

Em virtude da semelhança no consumo de matéria seca entre as dietas, o desempenho dos novilhos não foi alterado $(\mathrm{P}>0,05)$ com o aumento do teor de inclusão de farelo do mesocarpo de babaçu no concentrado, determinando semelhante peso corporal dos animais ao término do experimento (Tabela 4). Cabe destacar que as taxas de ganho de peso verificadas foram próximas às citadas na literatura nacional para bovinos Nelore (LEME et al., 2000; RESENDE et al.,
2001). Da mesma maneira, a conversão alimentar não foi alterada $(\mathrm{P}<0,05)$ pelo aumento do teor de inclusão de farelo do mesocarpo do babaçu no concentrado (Tabela 4), sendo o valor médio de $8,39 \mathrm{~kg}$ de matéria seca $\mathrm{kg}^{-1}$ de ganho de peso, valores condizentes com a categoria animal utilizada. Os resultados do presente estudo são próximos aos encontrados por EZEQUIEL et al. (2006), os quais não verificaram diferença para a conversão alimentar quando se substituiu o milho moído da dieta por casca de soja ou farelo de gérmen de milho, sendo o valor médio verificado de $7,86 \mathrm{~kg}$ de matéria seca $\mathrm{kg}^{1}$ de ganho peso, valor similar ao encontrado neste trabalho $\left(8,39 \mathrm{~kg}\right.$ de MS ingerida $\mathrm{kg}^{1}$ de ganho de peso).

O consumo das frações alimentares não foi alterado $(\mathrm{P}>0,05)$ pela condição sexual dos animais (Tabela 5), concordando com os resultados verificados por RESTLE et al. (1997) e RESTLE et al. (2000). Tais resultados corroboram a proposição do NRC (1996) que afirma que a condição sexual tem efeito limitado sobre a ingestão de alimentos.

Não foi verificado efeito $(\mathrm{P}>0,05) \mathrm{da}$ condição sexual sobre o peso inicial e final (Tabela 5). A falta de variação para o peso inicial era esperada, uma vez que as unidades experimentais foram selecionadas para serem homogêneas. Todavia, se esperava maior peso final dos machos não castrados em relação aos castrados, sendo que tais resultados podem estar associados ao curto período de 
Tabela 4 - Desempenho de bovinos confinados alimentados com teores crescentes de farelo do mesocarpo de babaçu no concentrado.

\begin{tabular}{|c|c|c|c|c|c|c|}
\hline \multirow{3}{*}{ Itens } & & & & & \multirow{3}{*}{$\mathrm{CV}, \%$} & \multirow{3}{*}{$\mathrm{P}$} \\
\hline & & & & & & \\
\hline & 0 & 20 & 40 & 60 & & \\
\hline Peso inicial, $\mathrm{kg}$ & 332,5 & 338,3 & 325,6 & 331,7 & 9,05 & 0,620 \\
\hline Peso final, kg & 430,8 & 429,5 & 414,1 & 424,2 & 7,74 & 0,496 \\
\hline Ganho de peso diário, $\mathrm{kg} \mathrm{dia}^{-1}$ & 1,229 & 1,140 & 1,106 & 1,156 & 15,2 & 0,622 \\
\hline Ganho de peso total, $\mathrm{kg}$ & 98,3 & 91,2 & 88,5 & 92,5 & 7,74 & 0,417 \\
\hline $\mathrm{CA}, \mathrm{kg}$ de $\mathrm{MS} \mathrm{kg}^{-1}$ de ganho de peso & 7,549 & 8,944 & 8,435 & 8,666 & 16,1 & 0,161 \\
\hline
\end{tabular}

$\mathrm{CA}=$ conversão alimentar; $\mathrm{MS}=$ matéria seca; $\mathrm{CV}=$ conversão alimentar; $\mathrm{P}=$ probabilidade

confinamento, nível nutricional da dieta e época de castração dos novilhos (60 dias antes do início do experimento). RESTLE et al. (1994) verificaram diferença no peso final de bovinos inteiros e castrados abatidos aos 25 meses de idade, apenas quando a castração foi realizada aos 1,5 meses de idade dos bezerros, sendo que a castração aos 8 e 12 meses não proporcionou diferenças no peso final entre castrados e não castrados. Segundo resultados de alguns estudos (RESTLE et al., 1994; RESTLE et al., 2000), a produção hormonal, em função da presença dos testículos, apresenta maior efeito na fase em que os animais têm maior incremento de peso (fase de crescimento, deposição de tecido muscular), proporcionado pelo melhor nível de alimentação.

O ganho de peso médio diário foi influenciado $(\mathrm{P}<0,05)$ pela condição sexual dos animais, sendo em média $184 \mathrm{~g} \mathrm{dia}^{-1}$ maior para machos não castrados em relação aos castrados, representando $14,72 \%$ a mais no ganho de peso médio diário (Tabela 5). Os resultados do presente estudo foram próximos aos verificados nos estudos de RESTLE et al. (1997) e RESTLE et al. (2000), que verificaram superioridade no ganho de peso médio diário dos animais não castrados em relação aos castrados em 12,8 e 13,7\%, respectivamente.

Os machos não castrados apresentaram melhor $(\mathrm{P}<0,05)$ conversão alimentar que os castrados, representando superioridade de 15,31\% em eficiência de utilização do alimento para ganho de peso diário (Tabela 5). Segundo citado por MACEDO et al. (2001), machos não castrados apresentam melhor eficiência alimentar que castrados em virtude da ação de hormônios esteroides no crescimento. BRONDANI

Tabela 5 - Consumo das frações alimentares e desempenho de bovinos confinados, em função da condição sexual.

\begin{tabular}{|c|c|c|c|c|}
\hline \multirow{2}{*}{ Variáveis } & ----Co & ual--------- & \multirow{2}{*}{$\mathrm{CV}, \%$} & \multirow{2}{*}{$\mathrm{P}$} \\
\hline & Inteiros & Castrados & & \\
\hline Consumo de matéria seca, $\mathrm{kg} \mathrm{dia}^{-1}$ & 9,524 & 9,562 & 8,1 & 0,909 \\
\hline Consumo de matéria seca, $\mathrm{g} \mathrm{kg}^{-1} \mathrm{PC}^{0,75}$ & 114,180 & 109,740 & 11,9 & 0,438 \\
\hline Consumo de matéria seca, \% PC & 2,680 & 2,480 & 13,5 & 0,349 \\
\hline Consumo de proteína bruta, $\mathrm{kg} \mathrm{dia}^{-1}$ & 1,298 & 1,310 & 7,6 & 0,787 \\
\hline Consumo de proteína bruta, $\mathrm{g} \mathrm{kg}^{-1} \mathrm{PC}^{0,75}$ & 15,630 & 15,110 & 11,7 & 0,492 \\
\hline Consumo de proteína bruta, \% PC & 0,360 & 0,340 & 13,3 & 0,397 \\
\hline Consumo de fibra em detergente neutro, $\mathrm{kg} \mathrm{dia}^{-1}$ & 3,945 & 3,996 & 8,9 & 0,733 \\
\hline Consumo de fibra em detergente neutro, $\mathrm{g} \mathrm{kg}^{-1} \mathrm{PC}^{0,75}$ & 47,410 & 45,960 & 13,0 & 0,578 \\
\hline Consumo de fibra em detergente neutro, \% PC & 1,070 & 1,040 & 15,4 & 0,598 \\
\hline Consumo de carboidratos não fibrosos, $\mathrm{kg} \mathrm{dia}^{-1}$ & 3,551 & 3,565 & 0,27 & 0,923 \\
\hline Consumo de carboidratos não fibrosos, $\mathrm{g} \mathrm{kg}^{-1} \mathrm{PC}^{0,75}$ & 41,260 & 41,760 & 0,07 & 0,445 \\
\hline Consumo de carboidratos não fibrosos, \% PC & 0,930 & 0,940 & 0,07 & 0,356 \\
\hline Peso inicial, $\mathrm{kg}$ & 330,000 & 333,200 & 4,7 & 0,721 \\
\hline Peso final, $\mathrm{kg}$ & 430,000 & 418,500 & 4,6 & 0,146 \\
\hline Ganho de peso médio diário, $\mathrm{kg} \mathrm{dia}^{1}$ & 1,250 & 1,066 & 13,8 & 0,013 \\
\hline Conversão alimentar, $\mathrm{kg}$ de $\mathrm{MS} \mathrm{kg}^{-1}$ de ganho de peso & 7,702 & 9,094 & 15,3 & 0,006 \\
\hline
\end{tabular}

$\mathrm{PC}=$ peso corporal; $\mathrm{MS}=$ matéria seca.

Ciência Rural, v.42, n.10, out, 2012. 
(2002) observou que a produção de bovinos jovens não castrados se justifica pelo maior ganho de peso (10 a 20\%), melhor eficiência alimentar (16\%) e maior rendimento de carcaça.

\section{CONCLUSÃO}

O farelo do mesocarpo do babaçu pode substituir até $60 \%$ do milho em concentrados para bovinos em confinamento. Bovinos inteiros apresentam maior ganho de peso e eficiência de utilização dos alimentos, atingindo peso de abate em menor tempo.

\section{COMITÊ DE ÉTICA E BIOSSEGURANÇA}

Ressaltamos que os animais foram mantidos em boas condições de alojamento e não havia nenhuma ação que causasse desconforto a eles. Assumimos a responsabilidade sobre qualquer questionamento futuro acerca do experimento. Desta forma, conto coma a compreensão do Comitê Editorial dessa revista para tramitação do artigo.

\section{REFERÊNCIAS}

ASSOCIATION OF OFFICIAL ANALYTICAL CHEMISTS (AOAC). Official methods of analysis. 15.ed. Washington, D.C., 1990. $1141 \mathrm{p}$.

BRONDANI, I.L. Desempenho e características de carcaça de bovinos jovens. 2002. 133f. Tese (Doutorado em Zootecnia) - Curso de Pós-graduação em Zootecnia, Universidade Estadual Paulista, SP.

EZEQUIEL, J.M.B. et al. Desempenho de novilhos Nelore alimentados com casca de soja ou farelo de gérmen de milho em substituição parcial ao milho moído. Revista Brasileira de Zootecnia. v.35, n.2, p.569-575, 2006. Disponível em: <http:/ /www.scielo.br/pdf/rbz/v35n2/a33v35n2.pdf>. Acesso em: 05 maio, 2011. doi: 10.1590/S1516-35982006000200033.

LEME, P.R. et al. Desempenho em confinamento e características de carcaça de bovinos machos de diferentes cruzamentos abatidos em três faixas de peso. Revista Brasileira de Zootecnia, v.29, n.6, p.2347-2353, 2000 (Suplemento 2).

MACEDO, M.P. et al. Característica de carcaça e composição corporal de touros jovens da raça Nelore terminados em diferentes sistemas. Revista Brasileira de Zootecnia, v.30, n.5, p.1610-1620, 2001. Disponível em: <http://www.scielo.br/ pdf/rbz/v30n5/6702.pdf>. Acesso em: 05 maio, 2011. doi 10.1590/S1516-35982001000600031.

MERTENS, D.R. Regulation of forage intake. In: FAHEY, G.C. et al. (Eds.). Forage quality: evaluation and utilization Madison, Winconsin: American Society Agronomy, 1994. p. $450-493$

MISSIO, R.L. et al. Desempenho e avaliação econômica da terminação de tourinhos em confinamento alimentados com diferentes níveis de concentrado na dieta. Revista Brasileira de Zootecnia, v.38, n.7, p.1309-1316, 2009. Disponível em: <http://www.scielo.br/pdf/rbz/v35n1/28374.pdf >. Acesso em 05 maio, 2011. doi: 10.1590/S1516-35982009000700021.
NATIONAL RESEARCH COUNCIL (NRC). Nutrient requirements of beef cattle. 7.ed. Washington, D.C.: National Academic of Sciences, 1996. 242p.

PACHECO, P.S. et al. Avaliação econômica em confinamento de novilhos jovens e superjovens de diferentes grupos genéticos. Revista Brasileira de Zootecnia, v.35, n.1, p.309-320, 2006. Disponível em: 〈http://www.scielo.br/pdf/rbz/v35n1/28374.pdf〉. Acesso em: 05 maio, 2011. doi: 10.1590/S1516-35982006000100039.

RESENDE, F.D. et al. Bovinos mestiços alimentados com diferentes proporções de volumoso: concentrado. 1 . Digestibilidade aparente dos nutrientes, ganho de peso e conversão alimentar. Revista Brasileira de Zootecnia, v.30, n.1, p.261-269, 2001. Disponível em: <http://www.scielo.br/ $\mathrm{pdf} / \mathrm{rbz} / \mathrm{v} 30 \mathrm{n} 1 / 5463$.pdf $>$. Acesso em: 05 maio, 2011. doi: 10.1590/S1516-35982001000100037.

RESTLE, J. et al. Evolução do peso de bovinos de corte inteiros ou castrados em diferentes idades. Pesquisa Agropecuária Brasileira, v.29, n.10, p.1631-1635, 1994.

RESTLE, J. et al. Desempenho em confinamento, do desmame ao abate aos 14 meses, de bovinos inteiros ou castrados, produzidos por vacas de dois anos. Ciência Rural, v.27, n.4, p.651-655, 1997.

RESTLE, J. et al. Características de carcaça de bovinos de corte inteiros ou castrados de diferentes composições raciais Charolês x Nelore. Revista Brasileira de Zootecnia, v.29, n.5, p.1371-1379, 2000. Disponível em: <http://www.scielo.br/ pdf/rbz/v29n5/5658.pdf >. Acesso em: 05 maio, 2011. doi: 10.1590/S1516-35982000000500015.

RESTLE, J. et al. Apreciação econômica da terminação em confinamento de novilhos Red Angus superjovens abatidos com diferentes pesos. Revista Brasileira de Zootecnia, v.36, n.4, p.978-986, 2007. Disponível em: <http://www.scielo.br/ pdf/rbz/v36n4/30.pdf >. Acesso em: 05 maio, 2011. doi: 10.1590/S1516-35982007000400030.

SILVA, N.R. Desempenho produtivo de bovinos de corte alimentados com dietas contendo diferentes níveis de farinha amilácea de babaçu. 2008. 75f. Dissertação (Mestrado em Ciência Animal Tropical) - Escola de Medicina Veterinária e Zootecnia, Universidade Federal do Tocantins, Araguaína.

SNIFFEN, C.J. et al. A net carbohydrate and protein system for evaluating cattle diets: II. Carbohydrate and protein availability. Journal of Animal Science, v.70, p.3562-3577, 1992.

STATISTICAL ANALYSES SYSTEM - SAS. User's guide statistics. Cary, N.C., 1993. 943p.

VALADARES FILHO, S.C. et al. Tabelas brasileiras de composição de alimentos para bovinos. CQBAL 2.0. Viçosa: Universidade Federal de Viçosa / Suprema Gráfica, 2006. 329p.

VAN SOEST, P.J. et al. Symposium: carbohydrate metodology, metabolism, and nutritional implications in dairy cattle. Journal of Dairy Science, v.74, n.10, p.3583-3597, 1991.

WILKINSON, J. Transformações e perspectivas dos agronegócios brasileiros. Revista Brasileira de Zootecnia, v.39, p.26-34, 2010 (supl. especial). Disponível em: <http:// www.scielo.br/pdf/rbz/v39sspe/04.pdf >. Acesso em: 05 maio, 2011. doi: 10.1590/S1516-35982010001300004. 